\title{
UC Berkeley launches landmark study
}

$\mathrm{R}$ esearchers with the UC Berkeley School of Public Health began interviewing pregnant women in the Salinas Valley in September for a landmark 5-year study on environmental health impacts to infants and children.

With $\$ 6.3$ million in funding from the U.S. Environmental Protection Agency (EPA), the Center for Children's Environmental Health Research will evaluate about 550 women during their pregnancies and track the impact of environmental exposures to pesticides, dust, endotoxins and allergens on the health of their children.

This is the first study to track human impacts of these low-dose environmental contaminants, says Dr. Max Cuevas, executive director of Clinica de Salud del Valle de Salinas, a partner in the research. Fittingly, the study is called CHAMACOS (Center for Health Assessment of Mothers and Children of Salinas), which means "small children" in Spanish.

Concerns about pesticide risks to children were also on EPA's agenda in August, when the agency issued the first restrictions under the Food Quality Protection Act. (See sidebar.)

Salinas was chosen because of earlier work between UC Cooperative Extension specialists and Clinica de Salud. The valley also has significant year-round agricultural production, Center associate director Asa Bradman says, including cooler-weather crops in the northern valley such as artichokes, lettuce and broccoli, and warmer-weather crops in the south such as peppers, tomatoes and grapes.

As a result, the population in the region is more stable, Bradman says, providing the opportunity for researchers to follow the mothers and their children over several years. While employment in agriculture is not required, the researchers expect many of the participating families to be farmworkers.

CHAMACOS has three main components:

Environmental exposures. Researchers will measure urinary levels of organophosphate pesticide metabolites in 550 pregnant women and children, and compare them to levels of local pesticide use, both agricultural and in the home. Mold, pollen, dust mites and other allergen samples will be collected from homes to assess their association to asthma and other respi- ratory diseases. (Pesticides will also be measured in a subset of dust samples.)

Health effects. To determine the relationship between neurodevelopment, growth and respiratory ailments, and environmental exposures during pregnancy and afterward, researchers will evaluate children from birth to 2 years of age. Mothers will be interviewed about their health, personal habits, demographics, migration patterns and work histories.

Intervention. In conjunction with community groups, researchers will develop educational materials and methods to reduce children's exposure to pesticides, allergens and other environmental contaminants.

The research is being conducted in partnership with the South County Outreach Group, Clinica de Salud and Natividad Medical Center in Salinas (led by Dr. Richard Brunader), as well as the Monterey County Health Department, several state and federal agencies, Stanford University and Children's Hospital of Oakland. The principal investigator and Center director is Brenda Eskenazi. - Janet Byron

\section{FQPA update}

On Aug. 2, the U.S. Environmental Protection Agency (EPA) announced the cancellation of methyl parathion for most food-crop uses, and reductions in the uses of azinphos methyl on a variety of fruits and vegetables.

The restrictions are the first significant regulatory actions taken under the Food Quality Protection Act (FQPA), a 1996 law that requires EPA to re-evaluate more than 9,000 pesticide tolerances to reduce health risks to infants and children.

Beginning in 2000, EPA will eliminate the use of methyl parathion on several fruit and vegetable crops, as well as all nonagricultural uses. For azinphos methyl, the allowable application rates were reduced for apples, pears and peaches.

Methyl parathion and azinphos methyl are both organophosphate pesticides, singled out by EPA for priority review because of their toxicity; EPA promised to complete its review of all 39 organophosphates, including atrazine, aldicarb and carbofuran, within 18 months. 